\title{
The association of matrix metalloproteinase-9 promoter polymorphisms with gastric cancer risk: a meta-analysis
}

\author{
Ziheng Peng ${ }^{1, *}$, Jinhai Jia ${ }^{2, *}$, Wenjian Gong ${ }^{1}$, Xuehan Gao ${ }^{1}$, Peiru Ma ${ }^{1}$, Zhucheng \\ $\mathrm{Jin}^{1}$, Yue Fan ${ }^{1}$, Yanchu $\mathrm{Li}^{1}$ and Xiaolin Zhang ${ }^{3}$ \\ ${ }^{1}$ Department of School of Basic Medical Sciences, Hebei Medical University, Shi Jiazhuang 050017, China \\ ${ }^{2}$ Department of Outpatient Clinic, Hebei Medical University, Shi Jiazhuang 050017, China \\ ${ }^{3}$ Department of Epidemiology and Statistics, School of Public Health, Hebei Medical University, Shi Jiazhuang 050017, China \\ "These authors contributed equally to this work
}

Correspondence to: Xiaolin Zhang, email: luckyzhang77@163.com

Keywords: gastric cancer, matrix metalloproteinase 9, meta-analysis, polymorphisms susceptibility risk

Received: April 25, 2017 Accepted: August 26, $2017 \quad$ Published: September 15, 2017

Copyright: Peng et al. This is an open-access article distributed under the terms of the Creative Commons Attribution License 3.0 (CC BY 3.0), which permits unrestricted use, distribution, and reproduction in any medium, provided the original author and source are credited.

\section{ABSTRACT}

Purpose: A variety of studies have observed that the single nucleotide polymorphisms (SNPs) matrix metalloproteinase-9 (MMP-9) gene may be associated with the risk of gastric cancer(GC), and a cytosine (C) to thymine (T) mutation at the $\mathbf{- 1 5 6 2}$ site of the MMP-9 gene promoter is reported to be closely related to the susceptibility. However, because of the conflicting results of these studies, we undertook a systematic meta-analysis to assess the association between the SNPs and the risk of gastric cancer.

Materials and Methods: A computerised literature search was conducted within the databases of PubMed, EMBASE, and ISI Web of Knowledge for studies on the genetic association of MMP-9-1562C/T and gastric cancer published from 2004 to 2015. The pooled odds ratio (OR) and $95 \%$ confidence intervals (CI) were estimated for each genotype using the dominant, recessive, co-dominant, and allelic models of the matrix metalloproteinase 9.

Results: Our analysis indicated a significant association of MMP-9-1562C/T with gastric cancer (dominant model $[C T+T T / C C]$ : $O R=1.121,95 \%$ CI $=0.965-1.304$; recessive model $[\mathrm{CC}+\mathrm{CT} / \mathrm{TT}]: \mathrm{OR}=1.663,95 \% \mathrm{CI}=1.148-2.408$; co-dominant model $[T T / C C]: O R=1.666,95 \% \mathrm{CI}=1.127-2.461 ;[\mathrm{CT} / \mathrm{CC}]: \mathrm{OR}=1.078,95 \% \mathrm{CI}=0.923-$ 1.259; allelic model $[T / C]:$ OR $=1.150,95 \% C I=1.014-1.304)$.

Conclusions: Our meta-analysis results demonstrated that MMP-9-1562C/T promoter polymorphisms increase the risk of developing gastric cancer.

\section{INTRODUCTION}

Gastric cancer is one of the most common cancers worldwide and one of the most common causes of cancer-related deaths in the developed world (fourth for men and fifth for women). An estimated 951,600 new stomach cancer cases occurred in 2012, as well as 723,100 deaths due to stomach cancer [1]. Multiple genetic and environmental factors may contribute to the incidence of gastric cancer. When the interaction of these factors leads to a series of mutations in the related genes of the body, abnormal cells may begin hyperplasia and a tumour forms.
Matrix metalloproteinases (MMPs) are a class of proteolytic enzymes that are closely related to tumorigenesis, invasion and metastasis. Depending on their substrate specificity and domain structure, MMPs can be divided into five divergent groups: collagenases, gelatinases, stromelysins, matrilysins and membrane-type MMPs [2]. Matrix metalloproteinase-9 is a gelatinase that is located on the long arm of the human chromosome $20 q 13.12$. Studies have found a cytosine (C) to thymine (T) mutation at the -1562 site of the MMP-9 gene promoter, which may affect the expression level of the MMP-9 gene. 
Recently, several studies have revealed that promoter polymorphisms of Matrix metalloproteinase-9, may contribute to gastric cancer in humans. The results by Japanese researchers in 2005 indicated that the $\mathrm{T}$ allele in the MMP-9 promoter is associated with the invasive phenotype of gastric cancer [3]. Recent studies performed by Chinese researchers in 2013 [4] and by Indian researchers in 2015 [5] have confirmed this result. In addition, these Chinese researchers [4] found that the genotype of MMP-9 is correlated with TNM classification and lymph node metastasis and plays an important role in the progression and metastasis of gastric cancer. In contrast to the abovementioned investigation, two additional studies published by Chinese researchers $[6,7]$, one additional study published by Indian researchers [8], and one study published by Turkish researchers [9] suggest no relevant association of MMP-9 with gastric cancer. Therefore, we conducted this meta-analysis to verify the association of MMP-9 SNPs with the risk of GC.

\section{MATERIALS AND METHODS}

\section{Literature and search strategy}

Our investigators independently conducted a systematic literature search in PubMed, Chinese National Knowledge Infrastructure (CNKI), EMBASE, WanFang (Chinese) Database, Chinese Biomedical Literature Database, and VIP (Chinese), with the last search update on January 1, 2017. We selected only studies in English and Chinese. We used the terms "(Gastric cancer) and (Matrix metalloproteinase 9)" or the equivalent Chinese terms to search the databases. In addition, we manually searched the reference lists of the included studies, as well as recent reviews, for further relevant studies (Figure 1).

\section{Inclusion criteria}

According to the following criteria, there were nine selected eligible studies in our meta-analysis: (1) evaluation of the association between matrix metalloproteinase-9 and risk of GC; (2) report of casecontrol studies or nested case-control studies; (3) and reported sufficiently detailed genotype data necessary to calculate odds ratio (OR) and $95 \%$ confidence intervals (CI). Investigators applied the inclusion criteria to each study by screening its title, abstract, and full text.

\section{Data extraction}

For each included study, the following information was collected: name of first author, year of publication, research design, geographical distribution of participants, ethnic background definitions, numbers of case and control groups, methods of DNA extraction and genotype. For studies that provided incomplete or no gene frequency data, the associated data for MMP-9 were obtained through genotype calculations. The data from each locus

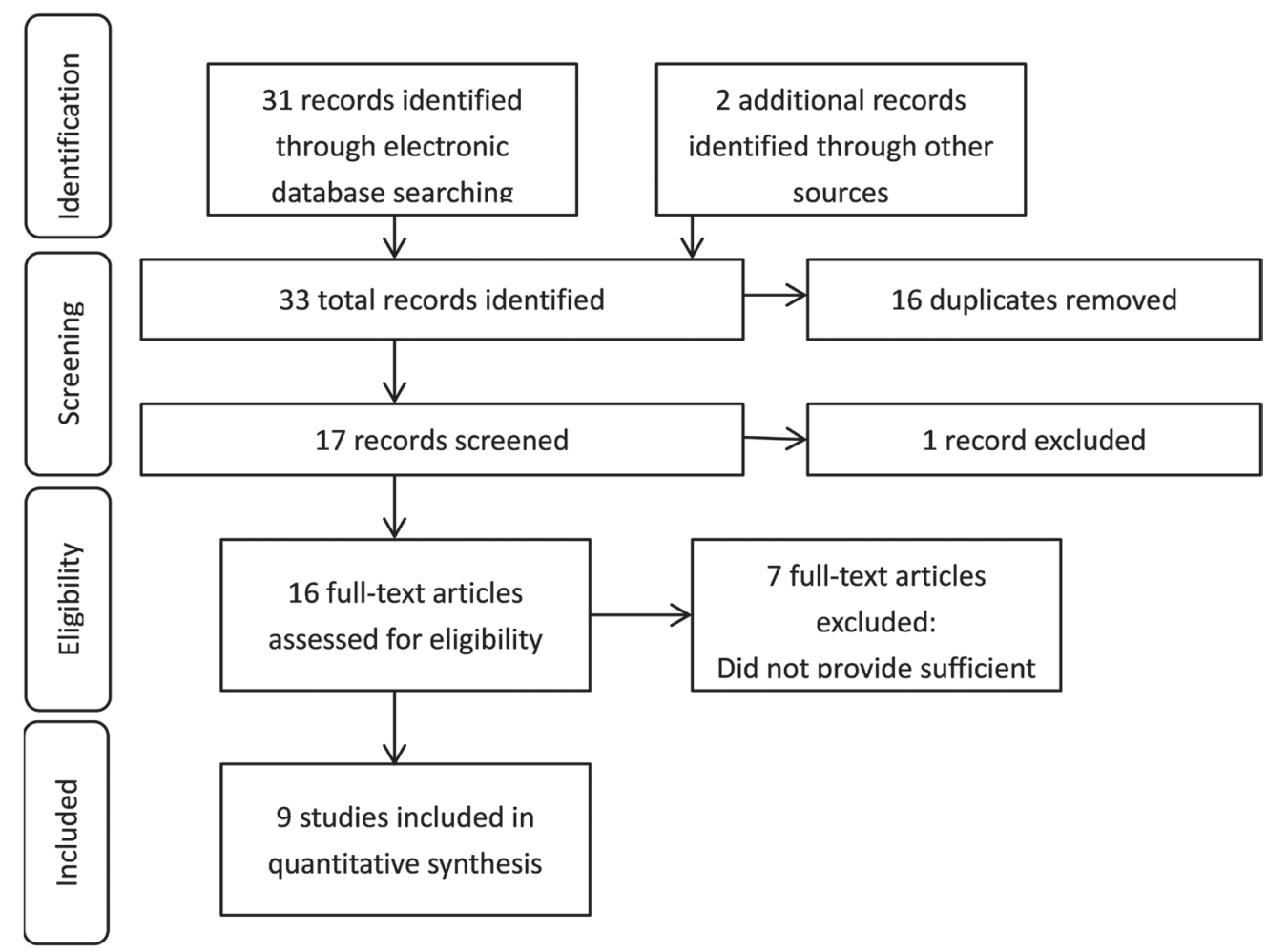

Figure 1: Flowchart summing the research and selection of articles for the meta-analysis. 
were divided into following two subgroups: gastric cancer and healthy control. Any dispute was resolved by discussion with all investigators.

\section{Statistical analysis}

In this article, we performed our meta-analysis on dominant, recessive, co-dominant and alleles genotype models of the MMP-9 locus. We calculated pooled OR with a $95 \%$ CI to evaluate the association of the locus with gastric cancer. First, we conducted a $Q$-test to assess the heterogeneity of each study. Second, according to heterogeneity results, we used either the Mantel-Haenszel fixed-effects model [10] or the DerSimonian-Laird randomeffects model [11] to calculate the pooled OR with a $95 \% \mathrm{CI}$. We considered a $P$ value $<0.1$ as an indicator of significant heterogeneity for the random-effects model. For the fixedeffects model, a $P$ value $>0.1$ was used as an indicator of significant heterogeneity. In addition, we used a funnel plot and Egger's test to assess publication bias with a $P<0.1$ indicating statistical significance. All $P$-values were regarded as two sided. All aforementioned statistical analyses were completed using STATA version 10.0 software (STATA Corporation, College Station, TX, USA).

\section{RESULTS}

\section{Characteristics of eligible studies}

We chose a total of nine papers to estimate the association of MMP-9 polymorphisms with gastric cancer. The details of the research and selection process are presented in the flowchart shown in Figure 1. The gastric cancer group contained 1345 patients who had been diagnosed with gastric cardia cancer, gastric carcinoma, and gastric antrum carcinoma. The healthy population used as the control group contained 2210 patients. Therefore, 9 studies involving 1345 gastric cancer patients and 2210 healthy patients were analysed in this metaanalysis (Table 1).

In addition, we evaluated the quality of the included studies according to the Newcastle-Ottawa Scale (NOS) [12]. This scale was used to access the studies on three criteria: determination of either the exposure or the outcome of interest ( $0-3$ points), comparability of the groups (0-2 points) and selection of the study groups (0-4 points). The best possible score of this scale is 9 points. In this meta-analysis, two studies $[3,13]$ scored 8 points; six studies [4-6, 8, 9, 14] scored 7 points; and one study [7] scored 6 points.

\section{Association between MMP-9 polymorphism and GC susceptibility}

In this study, by conducting the combined analysis, we observed a statistical divergence between SNP MMP-9 and risk of GC in all genetic models (Table 2). The $\mathrm{T}$ allele of MMP-9 was significantly associated with GC, demonstrating a pooled OR of $1.150(95 \%$ $\mathrm{CI}=1.014-1.304$ ) (Figure 2 ). The TT genotype showed approximately a 1.666 -fold $(\mathrm{OR}=1.666,95 \% \mathrm{CI}=1.127-$ 2.461 ) increased risk of GC compared with the MMP-9 $\mathrm{CC}$ genotype (Figure 3 ). The results from the recessive genotype models showed similar conclusions (OR: 1.663, 95\% CI $=1.148-2.408$ ) (Figure 4). However, the MMP-9 dominant genotype models showed no relationship with $\mathrm{GC}(\mathrm{OR}=1.121,95 \% \mathrm{CI}=0.965-1.304)$ (Figure 5). The results from CT genotype models showed similar

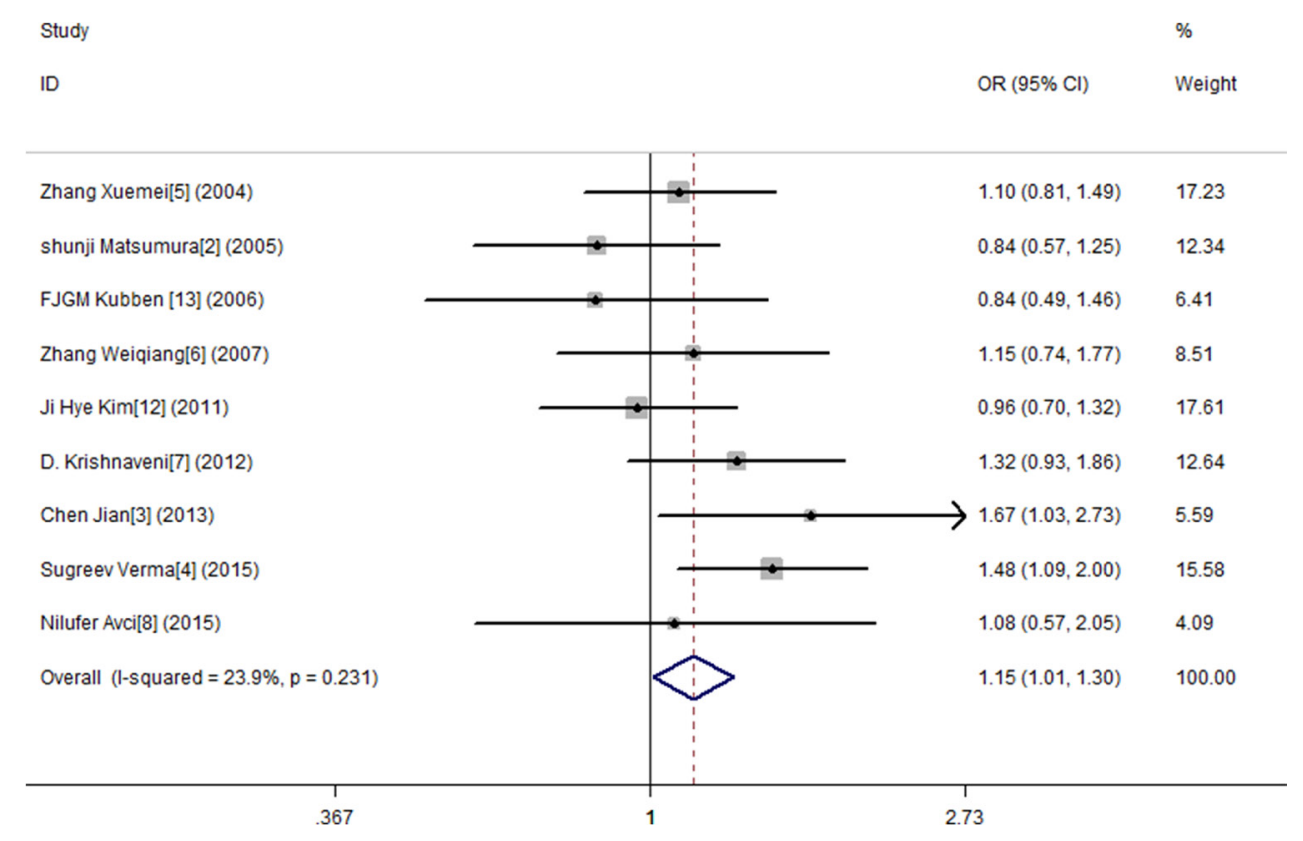

Figure 2: Meta-analysis forMMP9-1562 C/T polymorphism and gastric cancer susceptibility in allele genetic model. 
Table 1: Main characteristics of all eligible studies selected in the meta-analysis

\begin{tabular}{|c|c|c|c|c|c|}
\hline \multirow{2}{*}{ First author } & \multirow{2}{*}{ Publication year } & \multirow{2}{*}{ Ethnicity } & \multicolumn{2}{|c|}{ Number } & \multirow{2}{*}{ NOs } \\
\hline & & & Cases $^{\mathrm{a}}$ & Control $^{\mathrm{a}}$ & \\
\hline Chen Jian [3] & 2013 & Chinese & 98 & 100 & 7 \\
\hline Zhang Weiqiang [6] & 2007 & Chinese & 170 & 200 & 6 \\
\hline Zhang Xuemei [5] & 2004 & Chinese & 228 & 774 & 7 \\
\hline Shunji Matsumura [2] & 2005 & Japanese & 177 & 224 & 8 \\
\hline SugreevVerma [4] & 2015 & Indian & 230 & 233 & 7 \\
\hline NiluferAvci [8] & 2015 & Turkey & 79 & 65 & 7 \\
\hline D.Krishnaveni [7] & 2012 & Indian & 132 & 132 & 7 \\
\hline Ji Hye Kim [13] & 2011 & Asian & 152 & 313 & 8 \\
\hline FjgmKubben [12] & 2006 & European & 79 & 169 & 7 \\
\hline
\end{tabular}

${ }^{\mathrm{a}}$ Gastric cancer/health

Table 2: Main results of pooled ORs in the meta-analysis (comparison between patients with gastric cancer and healthy population)

\begin{tabular}{|c|c|c|c|}
\hline \multicolumn{2}{|c|}{ Genetic model } & \multirow{2}{*}{$\begin{array}{c}\text { OR }(\mathbf{9 5 \%} \mathbf{C I}) \\
1\end{array}$} & \multirow[t]{2}{*}{$P$ heterogeneity } \\
\hline Co-dominant model & $\mathrm{CC}$ & & \\
\hline & $\mathrm{CT}$ & $1.072(0.843,1.362)^{\mathrm{b}}$ & 0.025 \\
\hline & TT & $1.666(1.127,2.461)^{\mathrm{a}}$ & 0.991 \\
\hline Dominant model & $\mathrm{CT}+\mathrm{TT}$ vs. $\mathrm{CC}$ & $1.119(0.899,1.392)^{\mathrm{b}}$ & 0.050 \\
\hline Recessive model & $\mathrm{CC}+\mathrm{CT}$ vs. TT & $1.663(1.148,2.408)^{\mathrm{a}}$ & 0.967 \\
\hline Allele & C vs. T & $1.150(1.014,1.304)^{\mathrm{a}}$ & 0.231 \\
\hline
\end{tabular}

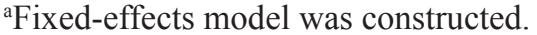

${ }^{b}$ Random-effects model was constructed.

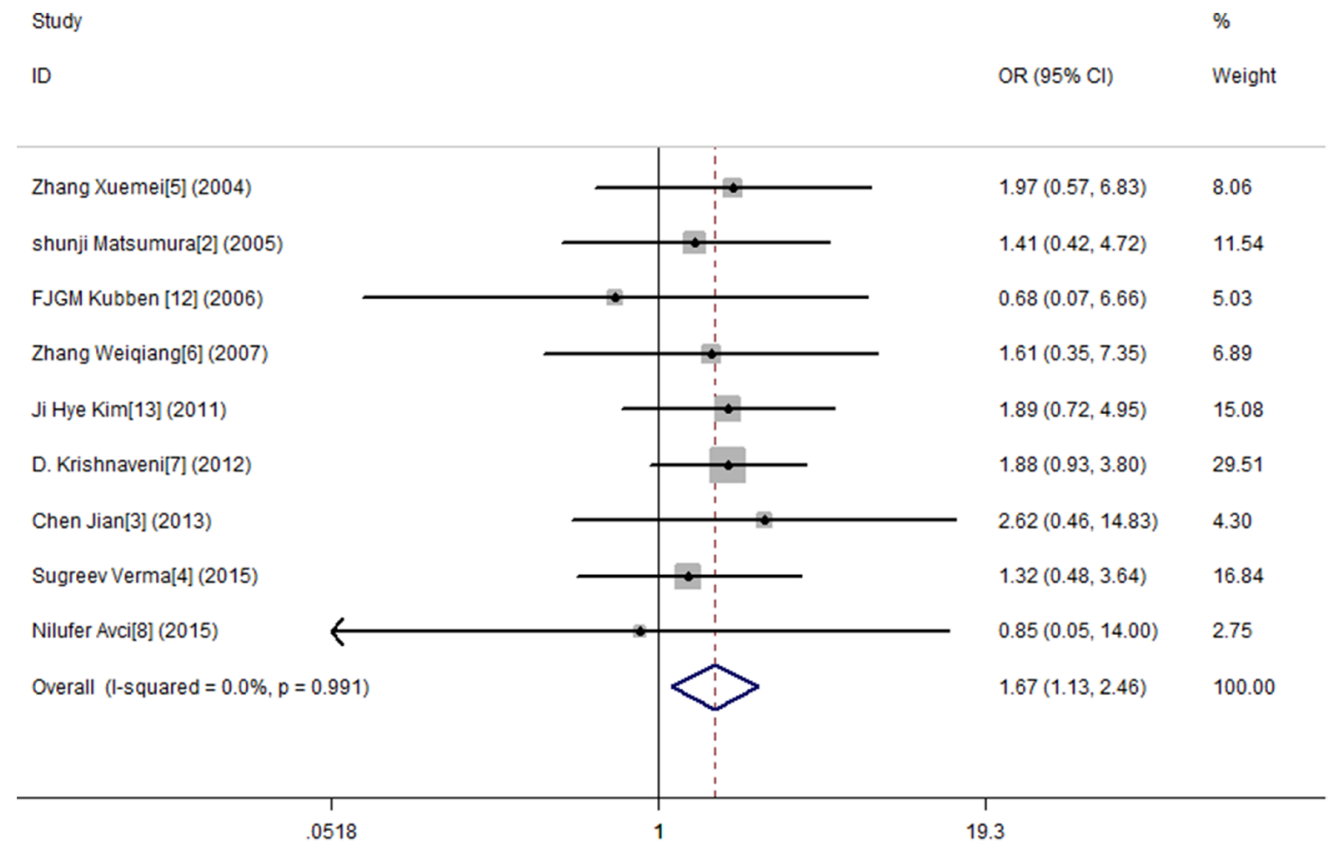

Figure 3: Meta-analysis for MMP9-1562 C/T polymorphism and gastric cancer susceptibility in co-dominant genetic model (TT). 
conclusions $(\mathrm{OR}=1.078,95 \% \mathrm{CI}=0.923-1.259)$ (Figure 6).

\section{Publication bias}

We employed the funnel plot and Egger's test to evaluate any potential publication bias. The shape of the funnel plots suggested no evident publication bias for MMP-9 among the co-dominant, dominant and recessive genotype models. A $P$ value $>0.1$ for Egger's test further verified these results (Figure 7).

\section{DISCUSSION}

The matrix metalloproteinases (MMPs) family comprises more than 20 enzymes and plays critical roles in cellular apoptosis, angiogenesis, tumour growth and metastasis. As essential regulators of the

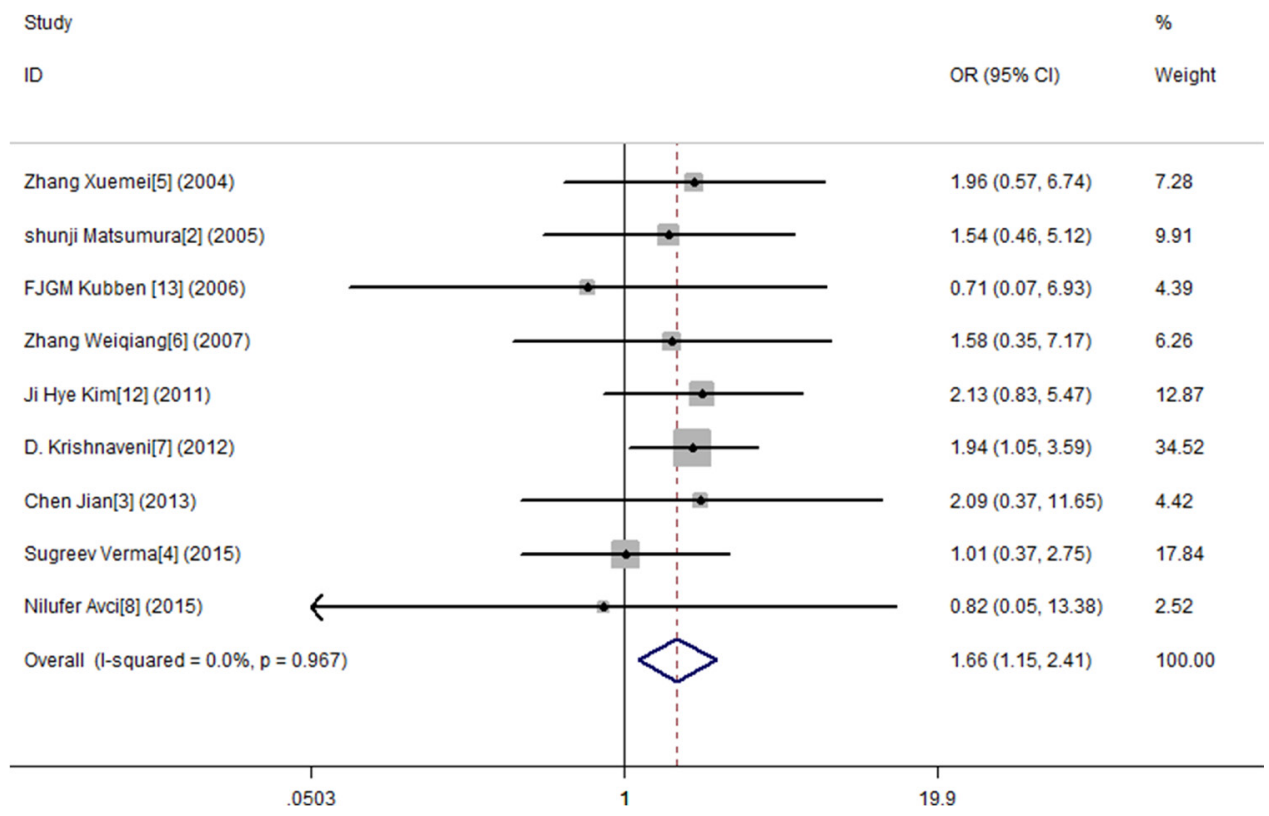

Figure 4: Meta-analysis for MMP9-1562 C/T polymorphism and gastric cancer susceptibility in recessive genetic model.

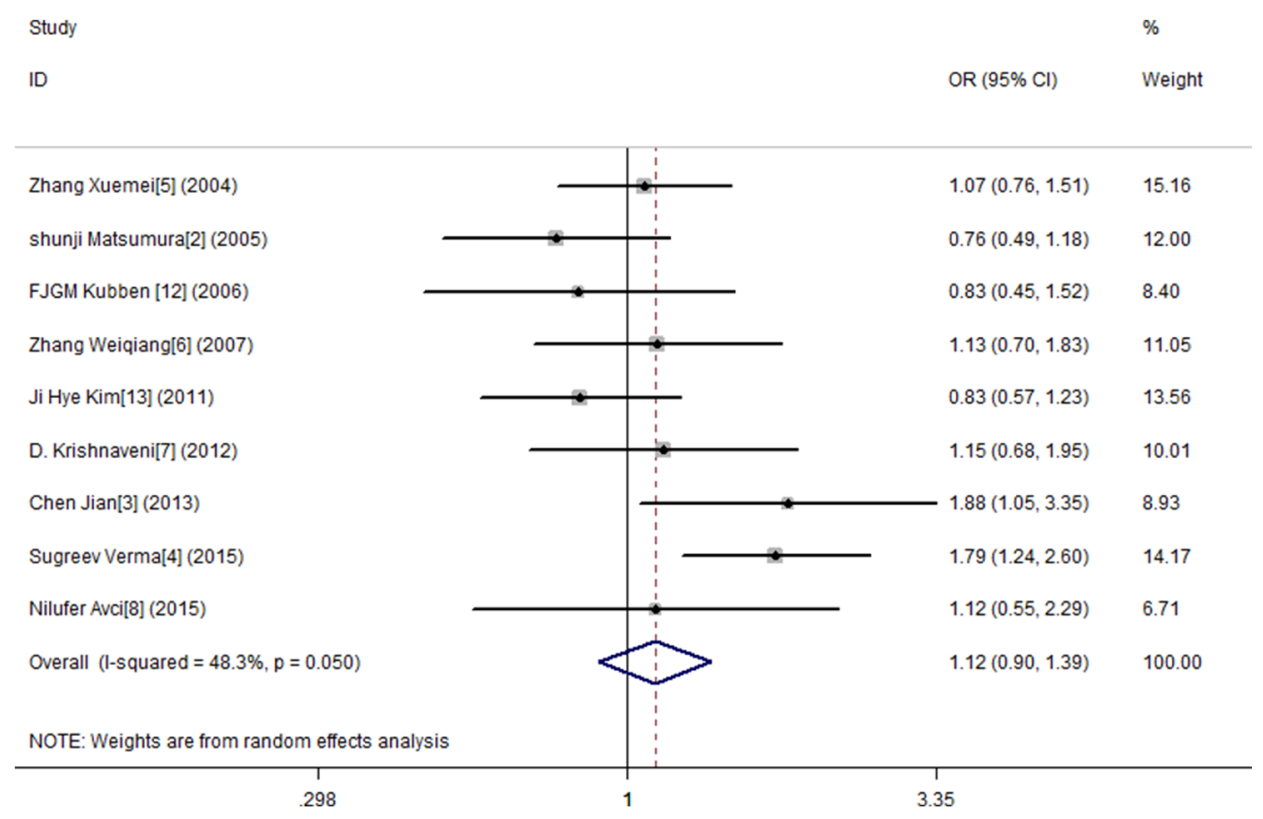

Figure 5: Meta-analysis for MMP9-1562 C/T polymorphism and gastric cancer susceptibility in dominant genetic model. 
microenvironment of the cell, MMPs are capable of degrading extracellular matrix (ECM) by cleaving it, which is considered as a barrier in cellular invasion [15]. The ECM of the gastric mucosa is composed of a number of macromolecules, such as collagen, laminin, proteoglycan, elastin, fibronectin and hyaluronic acid, and their degradation by MMPs play an important role in maintaining the cellular microenvironment [16]. The activity of MMPs is modulated by transcriptional regulation and their interaction with tissue inhibitors of metalloproteinases (TIMPs). MMPs and TIMPs play a key role in several steps of tumour dissemination and metastasis [17]. Expression of MMP genes can vary and affect the balance between synthesis and degradation of ECM proteins, which may contribute to the interindividual diversity of susceptibility to many complex diseases, including cancer [18].

Alveolar macrophages, polymorph nuclear leukocytes, osteoclasts and malignant cells primarily express MMP-9 [19], which is also known as gelatinase B

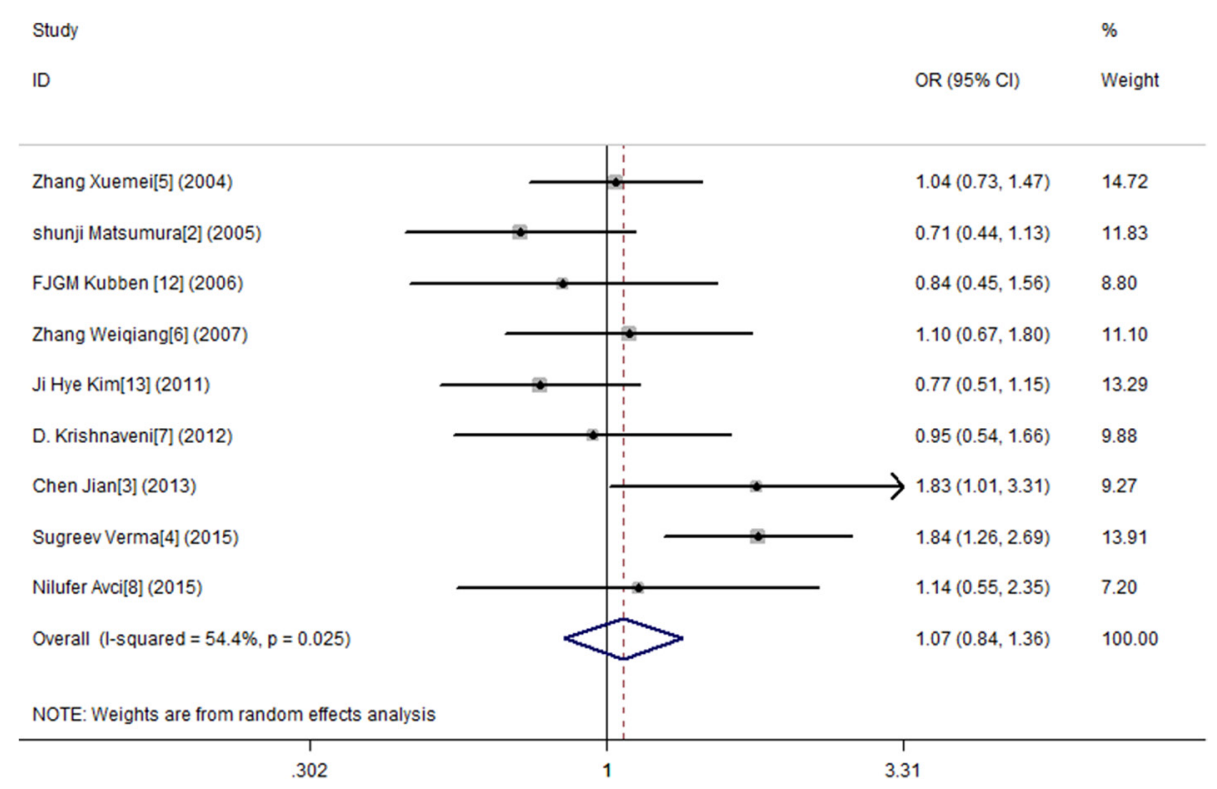

Figure 6: Meta-analysis for MMP9-1562 C/T polymorphism and gastric cancer susceptibility in co-dominant genetic model (CT).

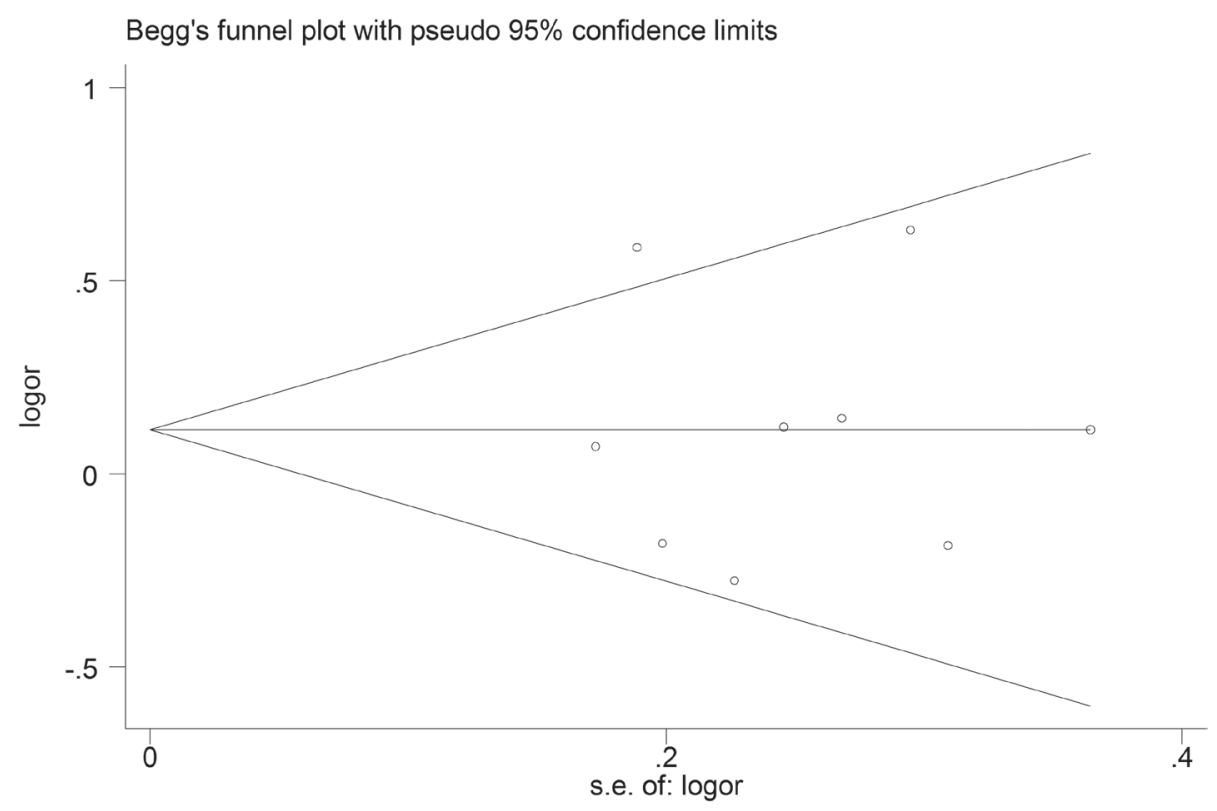

Figure 7: Funnel plots of the MMP-9 polymorphism studies: dominant model. No obvious funnel asymmetry was observed. Egger's test of the value from the funnel plot showed no statistical significance $(p=0.917)$. 
due to its ability to degrade collagen type IV, collagen type $\mathrm{V}$ and elastin. These cells secrete MMP-9 in an inactivated form as a $10 \mathrm{kDa}$ propeptide, and other MMPs or tissue plasminogen activator (tPA) plasmin system activate them [20, 21]. Additionally, under pathological conditions including gastrointestinal inflammation and gastric cancer, MMP-9 can be derived from stromal cells, such as inflammatory cells and fibroblasts [22, 23], and enhanced level of MMP-9 has been described. Furthermore, in vivo studies in MMP-9 deficient mice found that implanting MMP-9 expression in the bone marrow enhanced tumour metastasis, which could facilitate cancer cell migration by promoting angiogenesis [5].

MMP-9-1562C/T is one of the polymorphism positions in the MMP-9 gene promoter contig sequence. A cytosine $(\mathrm{C})$ to thymine $(\mathrm{T})$ transition at nucleotide -1562 in the promoter region of the MMP-9 gene generates low activity for $\mathrm{C} / \mathrm{C}$ and high activity for $\mathrm{C} / \mathrm{T}$ and $\mathrm{T} / \mathrm{T}$ genotypes in gene transcription [5]. The latter activities are confirmed by transient transfection experiments and DNA-protein interaction assays, which indicate that due to preferential binding of a putative transcription repressor protein to the $\mathrm{C}$ allelic promoter the $\mathrm{T}$ allele had a higher promoter activity than the $\mathrm{C}$ allele [24].

The activity of increasing MMP-9 could be downregulated by many extracellular factors, such as MMP-1, -3, -7, -10, -26, trypsin-2 and neutrophil elastase [25]. Among these, the most important endogenous inhibitor of MMP-9 is the tissue inhibitors of metalloproteinases 1 (TIMP-1), which blocks the cleavage effect of MMP-9 extracellularly. However, several studies have revealed that TIMP-1 also inhibits the membraneprotein shedding process and the cell signal regulatory effect of MMP-9 [26-28]. Because of its special properties, initially TIMP-1 was considered a tumour suppressing gene. Later, researchers found that TIMP1 also functions independently of MMP-9 to promote tumour growth and inhibit apoptosis [29].

Some studies have found a protective effect against digestive cancers [30] and lung cancer [31] for MMP-9 polymorphism, but its effects in prostate cancer vary [32]. Recently, some results [33] have provided new evidence that the imbalance of MMP-9/ TIMP-1 is one of the regulation mechanisms to promote tumourigenicity and metastasis of prostate cancer cells. However, other researchers hold a different opinion and the causal mechanism of this imbalance remains unclear. In addition, in the past two years, an increasing number of studies have revealed the relationship between MMP-9 and oesophageal squamous cell carcinoma [34], ovarian cancer [35], nasopharyngeal carcinoma [36, 37], Ewing sarcoma [38], and bladder cancer [39]. Different microenvironments and tissue interactive mechanisms may lead to the presence of the divergence. By conducting studies with larger sample sizes and better consideration of environmental factors, researchers can make progress in determining the cariogenic effect of these polymorphisms.

The present study had some limitations that must be discussed. First, although we collected all eligible studies, the number of studies was small, which meant that analyses may not have had enough statistical power to explore the association of these polymorphisms with cancer susceptibility. As we all known, any interpretation of meta-analysis must be bounded within its limited context, and thus, only further and larger-scaled studies can lessen the likelihood of type I and type II errors. Second, the lack of available information about adjusted ORs by age, gender, smoking status and different histological types of gastric cancer, especially diets and alcohol consumption, prevented a more precise evaluation. Objectively speaking, it is necessary to evaluate the roles of those special environmental and lifestyle factors. Third, we cannot ignore the possible existence of genegene interactions. Ideally, we should evaluate the gene only after determining the roles of MMPs' inhibitors, such as TIMP-1, TIMP-2, TIMP-3, and TIMP-4, in the development of gastric cancer. Moreover, some polymorphisms may play different roles in different tissues among people with different genetic backgrounds. A lack of data on ethnicity analysis prevented us from conducting a subgroup analysis on different populations. In spite of this, our meta-analysis has several strengths. First, our results arise from an analysis that combined the data of several studies rather than evaluating the studies independently. This significantly enhanced the statistical power of the analysis and helped us to reach a more reliable conclusion. Second, we tested publication bias and detected none, which indicates a minimised chance of misleading results.

In conclusion, the results of our meta-analysis demonstrated that promoter region polymorphisms of the MMP-9 gene were associated with the susceptibility of gastric cancer. More comprehensive studies may eventually result in a better understanding of the association of MMP9-1562C/T polymorphisms with gastric cancer.

\section{CONFLICTS OF INTEREST}

The authors have declared no conflicts of interest.

\section{FUNDING}

Youth fund projects of education department of Hebei province (QN2015010). The scientific research project of Hebei education department (Z2012079)

\section{REFERENCES}

1. Singh P, Toom S, Huang Y. Anti-claudin 18.2 antibody as new targeted therapy for advanced gastric cancer. J Hematol Oncol. 2017; 10:105. 
2. Peng B, Cao L, Ma X, Wang W, Wang D, Yu L. Metaanalysis of association between matrix metalloproteinases 2, 7 and 9 promoter polymorphisms and cancer risk. Mutagenesis. 2010; 25:371-379.

3. Matsumura S, Oue N, Nakayama H, Kitadai Y, Yoshida K, Yamaguchi Y, Imai K, Nakachi K, Matsusaki K, Chayama $\mathrm{K}$, Yasui W. A single nucleotide polymorphism in the MMP-9 promoter affects tumor progression and invasive phenotype of gastric cancer. J Cancer Res Clin. 2005; 131:19-25.

4. Jian C, Fei Q, Ying H, Lei Z. The study on the relationship between polymorphism of MMP-9 and gastric cancer. Modern Preventive Medicine. 2013; 2329-2333.

5. Verma S, Kesh K, Gupta A, Swarnakar S. An Overview of Matrix Metalloproteinase 9 Polymorphism and Gastric Cancer Risk. Asian Pac J Cancer P. 2015; 16:7393-7400.

6. Xuemei Z, Xiaoping M, Ping X, Chunyuan Y, Tan Wen QS, Tong S, Yifeng Z, Dongxin L. Association of Functional Polymorphisms in Matrix Metalloproteinase-2 (MMP-2) and MMP-9 Genes With Risk of Gastric Cancer in A Chinese Population. [Article in Chinese]. Ai Zheng. 2004; 1233-1237.

7. Weiqiang $Z$, Jing $Z$, Yong'an $Z$, Lianhong $C$, Guoqiang B. Association of polymorphisms in matrix metalloproteinase- 9 and risk of cardiac cancer and gastric cancer. [Article in Chinese]. The Journal Of Practical Medicine. 2007; 2859-2861.

8. Krishnaveni D, Bhayal AC, Sri Manjari K, Vidyasagar A, Uma Devi M, Ramanna M, Jyothy A, Nallari P, Venkateshwari A. MMP 9 Gene Promoter Polymorphism in Gastric Cancer. Indian Journal of Clinical Biochemistry. 2012; 27:259-264.

9. Avcı N, Ture M, Deligonul A, Cubukcu E, Olmez OF, Sahinturk S, Topak A, Kurt E, Evrensel T, Şahin AB, Yakut T. Association and Prognostic Significance of the Functional $-1562 \mathrm{C} / \mathrm{T}$ Polymorphism in the Promoter Region of MMP-9 in Turkish Patients with Gastric Cancer. Pathol Oncol Res. 2015; 21:1243-1247.

10. Mantel N, Haenszel W. Statistical aspects of the analysis of data from retrospective studies of disease. J Natl Cancer Inst. 1959; 22:719-748.

11. DerSimonian R, Laird N. Meta-analysis in clinical trials. Control Clin Trials. 1986; 7:177-188.

12. Stang A. Critical evaluation of the Newcastle-Ottawa scale for the assessment of the quality of nonrandomized studies in meta-analyses. Eur J Epidemiol. 2010; 25:603-605.

13. Kubben FJ, Sier CF, Meijer MJ, van den Berg M, van der Reijden JJ, Griffioen G, van de Velde CJ, Lamers CB, Verspaget HW. Clinical impact of MMP and TIMP gene polymorphisms in gastric cancer. Br J Cancer. 2006; 95:744-751.

14. Kim J, Pyun J, Cho SW, Lee K, Kwack K. Lymph Node Metastasis of Gastric Cancer Is Associated with the Interaction Between Poly (ADP-Ribose) Polymerase 1 and Matrix Metallopeptidase 2. Dna Cell Biol. 2011; 30:1011-1017.

15. Sternlicht MD, Werb Z. How matrix metalloproteinases regulate cell behavior. Annu Rev Cell Dev Biol. 2001; 17:463-516.
16. Hellmig S, Ott S, Rosenstiel P, Robert FU, Hampe J, Schreiber S. Genetic variants in matrix metalloproteinase genes are associated with development of gastric ulcer in H. Pylori infection. Am J Gastroenterol. 2006; 101:29-35.

17. Ye S. Polymorphism in matrix metalloproteinase gene promoters: implication in regulation of gene expression and susceptibility of various diseases. Matrix Biol. 2000; 19:623-629.

18. Zhang B, Henney A, Eriksson P, Hamsten A, Watkins H, Ye S. Genetic variation at the matrix metalloproteinase-9 locus on chromosome 20q12.2-13.1. Hum Genet. 1999; 105:418-423.

19. Fanjul-Fernandez M, Folgueras AR, Cabrera S, Lopez-Otin C. Matrix metalloproteinases: evolution, gene regulation and functional analysis in mouse models. Biochim Biophys Acta. 2010; 1803:3-19.

20. Shi M, Cao M, Song J, Liu Q, Li H, Meng F, Pan Z, Bai J, Zheng J. PinX1 inhibits the invasion and metastasis of human breast cancer via suppressing NF-kappaB/MMP-9 signaling pathway. Mol Cancer. 2015; 14:66.

21. Xia Y, Lian S, Khoi PN, Yoon HJ, Joo YE, Chay KO, Kim KK, Do JY. Chrysin inhibits tumor promoter-induced MMP-9 expression by blocking AP-1 via suppression of ERK and JNK pathways in gastric cancer cells. Plos One. 2015; 10:e124007.

22. Itoh T, Tanioka M, Matsuda H, Nishimoto H, Yoshioka T, Suzuki R, Uehira M. Experimental metastasis is suppressed in MMP-9-deficient mice. Clin Exp Metastasis. 1999; 17:177-181.

23. Yu Q, Stamenkovic I. Cell surface-localized matrix metalloproteinase-9 proteolytically activates TGF-beta and promotes tumor invasion and angiogenesis. Genes Dev. $2000 ; 14: 163-176$.

24. Li X, Qu L, Zhong Y, Zhao Y, Chen H, Daru L. Association between promoters polymorphisms of matrix metalloproteinases and risk of digestive cancers: a metaanalysis. J Cancer Res Clin Oncol. 2013; 139:1433-1447.

25. Van den Steen PE, Dubois B, Nelissen I, Rudd PM, Dwek RA, Opdenakker G. Biochemistry and molecular biology of gelatinase B or matrix metalloproteinase-9 (MMP-9). Crit Rev Biochem Mol Biol. 2002; 37:375-536.

26. Stetler-Stevenson WG. Tissue inhibitors of metalloproteinases in cell signaling: metalloproteinaseindependent biological activities. Sci Signal. 2008; 1:e6.

27. Brew $K$, Nagase $H$. The tissue inhibitors of metalloproteinases (TIMPs): an ancient family with structural and functional diversity. Biochim Biophys Acta. 2010; 1803:55-71.

28. Hornebeck W, Lambert E, Petitfrere E, Bernard P. Beneficial and detrimental influences of tissue inhibitor of metalloproteinase-1 (TIMP-1) in tumor progression. Biochimie. 2005; 87:377-383.

29. Ries C. Cytokine functions of TIMP-1. Cell Mol Life Sci. 2014; 71:659-672.

30. Li X, Qu L, Zhong Y, Zhao Y, Chen H, Daru L. Association between promoters polymorphisms of matrix 
metalloproteinases and risk of digestive cancers: a metaanalysis. J Cancer Res Clin Oncol. 2013; 139:1433-1447.

31. Zhang LF, Mi YY, Cao Q, Wang W, Qin C, Wei JF, Zhou YJ, Li YF, Tang M, Liu WM, Zhang W, Zou JG. Update analysis of studies on the MMP-9 -1562 C\&gt; T polymorphism and cancer risk. Mol Biol Rep. 2012; 39:3435-3441.

32. Sfar S, Saad H, Mosbah F, Gabbouj S, Chouchane L. TSP1 and MMP9 genetic variants in sporadic prostate cancer. Cancer Genet Cytogenet. 2007; 172:38-44.

33. Chen CM, Lin CL, Chiou HL, Hsieh SC, Lin CL, Cheng CW, Hung CH, Tsai JP, Hsieh YH. Loss of endothelial cell-specific molecule 1 promotes the tumorigenicity and metastasis of prostate cancer cells through regulation of the TIMP-1/MMP9 expression. Oncotarget. 2017; 8:13886-13897. https://doi. org/10.18632/oncotarget.14684.

34. Shin WS, Hong Y, Lee HW, Lee ST. Catalytically defective receptor protein tyrosine kinase PTK7 enhances invasive phenotype by inducing MMP-9 through activation of AP-1 and NF-kappaB in esophageal squamous cell carcinoma cells. Oncotarget. 2016; 7:73242-73256. https://doi. org/10.18632/oncotarget.12303.

35. Carroll MJ, Kapur A, Felder M, Patankar MS, Kreeger PK. M2 macrophages induce ovarian cancer cell proliferation via a heparin binding epidermal growth factor/ matrix metalloproteinase 9 intercellular feedback loop.
Oncotarget. 2016; 7:86608-86620. https://doi.org/10.18632/ oncotarget. 13474 .

36. Chu WK, Hsu CC, Huang SF, Hsu CC, Chow SE. Caspase 12 degrades IkBa protein and enhances MMP9 expression in human nasopharyngeal carcinoma cell invasion. Oncotarget. 2017; 8:33515-33526. https://doi. org/10.18632/oncotarget.16535.

37. Liu T, Wu X, Wang Y, Zhang T, Wu T, Liu F, Wang W, Jiang G, Xie M. Folate-targeted star-shaped cationic copolymer co-delivering docetaxel and MMP-9 siRNA for nasopharyngeal carcinoma therapy. Oncotarget. 2016; 7:42017-42030. https://doi.org/10.18632/oncotarget.9771.

38. Lagares-Tena L, Garcia-Monclus S, Lopez-Alemany R, Almacellas-Rabaiget O, Huertas-Martinez J, Sainz-Jaspeado M, Mateo-Lozano S, Rodriguez-Galindo C, Rello-Varona S, Herrero-Martin D, Tirado OM. Caveolin-1 promotes Ewing sarcoma metastasis regulating MMP-9 expression through MAPK/ERK pathway. Oncotarget. 2016; 7:56889-56903. https://doi.org/10.18632/oncotarget.10872.

39. Falzone L, Candido S, Salemi R, Basile MS, Scalisi A, McCubrey JA, Torino F, Signorelli SS, Montella M, Libra M. Computational identification of microRNAs associated to both epithelial to mesenchymal transition and NGAL/ MMP-9 pathways in bladder cancer. Oncotarget. 2016; 7:72758-72766. https://doi.org/10.18632/oncotarget.11805. 